Tropical Journal of Pharmaceutical Research May 2015; 14(5): 859-867

ISSN: $1596-5996$ (print); 1596-9827 (electronic)

(C) Pharmacotherapy Group, Faculty of Pharmacy, University of Benin, Benin City, 300001 Nigeria.

All rights reserved.

Available online at http://www.tjpr.org

Original Research Article

http://dx.doi.org/10.4314/tjpr.v14i5.17

\title{
Discrete Wavelet Transform-Partial Least Squares Versus Derivative Ratio Spectrophotometry for Simultaneous Determination of Chlorpheniramine Maleate and Dexamethasone in the Presence of Parabens in Pharmaceutical Dosage Form
}

\author{
Hany W Darwish ${ }^{1,2 *}$, Fadia H Metwally ${ }^{2,3}$ and Abdelaziz El Bayoumi ${ }^{2}$ \\ ${ }^{1}$ Department of Pharmaceutical Chemistry, College of Pharmacy, King Saud University, PO Box 2457, Riyadh 11451, Saudi \\ Arabia, ${ }^{2}$ Department of Analytical Chemistry, Faculty of Pharmacy, Cairo University, Kasr El-Aini Street, ET 11562, Cairo, \\ Egypt, ${ }^{3}$ Ibn Sina National College for Medical Studies, AIMahjer Road, Jeddah, Saudi Arabia
}

*For correspondence: Email: hdarwish75@yahoo.com, hdarwish@ksu.edu.sa; Tel: +966-14677343; Fax: +966-14676220

\begin{abstract}
Purpose: To compare two methods, based on different approaches, for simultaneous determination of chlorpheniramine maleate (CHP) and dexamethasone (DX) in the presence of methyl and propyl paraben in phenadone syrup.

Methods: The first method used, based on univariate calibration approach, was first derivative of the ratio spectrophotometry (DD1). The second method, which is a multivariate calibration approach, was discrete wavelet transform followed by partial least squares method (DWT-PLS) which anticipated high predictive ability for the determination of both CHP and DX.

Results: DD1 method failed to determine $D X$ due to the absence of adequate zero crossing point while DWT-PLS method was successfully applied for the analysis of raw materials and the dosage form. For DD1 method, recovery of chlorpheniramine maleate in the dosage form was $100.33 \pm 0.91 \%$ while for DWT-PLS method, recovery of chlorpheniramine maleate and dexamethasone was $100.24 \pm 1.21$ and $99.99 \pm 1.08 \%$, respectively. The proposed methods were validated using standard addition technique and the results compared favorably with those obtained by a reference high performance liquid chromatography (HPLC) method.

Conclusion: The findings of this work show the superiority of DWT-PLS over DD1 method in solving such complex mixtures, and would thus be suitable for use in quality control (QC) laboratories and pharmaceutical industry.
\end{abstract}

Keywords: Quantitative analysis, Discrete wavelet transform, First derivative of ratio spectra, Chlorpheniramine maleate, Dexamethasone

Tropical Journal of Pharmaceutical Research is indexed by Science Citation Index (SciSearch), Scopus, International Pharmaceutical Abstract, Chemical Abstracts, Embase, Index Copernicus, EBSCO, African Index Medicus, JournalSeek, Journal Citation Reports/Science Edition, Directory of Open Access Journals (DOAJ), African Journal Online, Bioline International, Open-J-Gate and Pharmacy Abstracts

\section{INTRODUCTION}

Although HPLC and other conventional spectrophotometric methods have been extensively applied to the simultaneous analysis of pharmaceutical mixtures, they have some well-known disadvantages in the analytical applications. However, the emerging of the new mathematical methods, namely the wavelet transforms (WT) [1-3] and the chemometric methods [4] developed the resolution of the overlapping peaks in the spectra of multi- 
mixtures. WT is a recent signal processing technique [5]. Many applications of WT in chemistry appeared in the literature such as resolution of overlapped chromatographic peaks [6], signal denoising [7] and multivariate calibration $[8,9]$.

Previously, derivative spectrophotometry was a comparative technique for the quantitation of multi-mixtures. But due to its various disadvantages, including fair resolution of mixture spectra with higher order, new methods (such as WT) have been proposed for the quantitative and routine analysis of the drugs in their samples. Hence the aim of this work is to highlight the algorithm, advantages and the merits of WT on increasing the predictive power of multivariate calibration methods. The second aim is to show the superiority of WT over the first derivative of ratio spectra method $\left(D D^{1}\right)$ in the quantitation of multi-mixtures.

The comparison is conducted on a pharmaceutical data set; chlorpheniramine maleate (CHP) and dexamethasone (DX) in presence of methyl paraben (MP) and propyl paraben (PP) as a case study. CHP is an antihistaminic drug while DX is a corticosteroid anti-inflammatory agent [10]. Simultaneous determination of the two analytes in their combined tablets were reported by HPLC methods [11, 12], spectrofluorimetric method [13] chemometric methods [14] and derivative spectrophotometric method [15].

\section{EXPERIMENTAL}

\section{Instruments}

A double beam UV-visible spectrophotometer (SHIMADZU, Japan) model UV-1601 PC with quartz cell of $1 \mathrm{~cm}$ pathlength, connected to IBM compatible computer. The software was UVPC personal spectroscopy software version 3.7. The spectral bandwidth was $2 \mathrm{~nm}$ and wavelengthscanning speed $2800 \mathrm{~nm} / \mathrm{min}$.

\section{Software}

All multivariate calibration methods were implemented in Matlabß 7.1.0.246 (R14) using wavelet toolbox and PLS toolbox software version 2.1. The $t$ test, $F$ test and ANOVA test were performed using Microsoft@ Excel 2013. All calculations were performed using intel $\AA_{\text {core }}{ }^{\mathrm{TM}}$ i5-2400, 3.10 GHz, 4.00 GB of RAM under Microsoft Windows 7.

\section{Reagents and chemicals}

Reference chlorpheniramine maleate (CHP), dexamethasone (DX), methyl paraben (MP) and propyl paraben (PP) certified to contain $99.59 \%$, $99.73 \%, 98.50 \%$ and $101.65 \%$ respectively by the manufacturer method were kindly provided by The Arab Pharmaceuticals and Chemical Industries Company, Cairo, Egypt. Phenadone syrup is kindly supplied by the manufacturer (The Arab Drug Co.) and it is labeled to contain 0.4 $\mathrm{mg} \mathrm{mL}^{-1} \mathrm{CHP}, 0.1 \mathrm{mg} \mathrm{mL}^{-1} \mathrm{DX}, 1 \mathrm{mg} \mathrm{mL}^{-1} \mathrm{MP}$ and $0.2 \mathrm{mg} \mathrm{mL}^{-1} \mathrm{PP}$, batch no. 630351. Methanol and $0.1 \mathrm{~N} \mathrm{HCl}$ used were of spectroscopic grade.

\section{Standard stock and working solutions}

Stock standard solutions of CHP, DX, MP and PP were prepared separately by dissolving 100 $\mathrm{mg}$ of CHP, $50 \mathrm{mg} \mathrm{DX}, 50 \mathrm{mg} \mathrm{MP}$ and $100 \mathrm{mg}$ $\mathrm{PP}$ in $100 \mathrm{~mL}$ methanolic $\mathrm{HCl}$ (1 $\mathrm{mL}$ methanol: 4 $\mathrm{mL} 0.1 \mathrm{~N} \mathrm{HCl}$ ). Corresponding working solutions were prepared by transferring accurately $25 \mathrm{~mL}$ from each stock standard solutions separately in $250 \mathrm{~mL}$ measuring flasks and volume was completed with methanolic $\mathrm{HCl}$. Solutions (xc) and $(\mathrm{xd})\left\{0.125 \mathrm{mg} \mathrm{mL}^{-1}\right\}$ were also prepared by methanolic $\mathrm{HCl}$.

\section{Calibration procedures}

\section{$D D^{1}$ spectrophotometric method}

\section{Determination of the analytical wavelengths}

The absorption spectra of the solutions of standard drug CHP, DX, MP and PP $\left(10 \mu \mathrm{g} \mathrm{mL}^{-1}\right)$ were recorded between 200-300 $\mathrm{nm}$. The first derivatives of the ratio-spectra of CHP/MP, DX/MP were recorded (standard divisor, MP 12 $\mu \mathrm{g} \mathrm{mL}^{-1}$ was used) smoothed at scaling factor 10 and $\Delta \lambda=4 \mathrm{~nm}$, then the selected zero-crossing wavelengths were determined and found to be $261.6 \mathrm{~nm}$ for CHP and 248.1 $\mathrm{nm}$ for DX.

\section{Construction of calibration curves}

Accurately measured portions of each of CHP and DX solutions equivalent to 10 - 30 and 5 - 14 $\mu \mathrm{g} \mathrm{mL}^{-1}$, respectively, were transferred separately to a series of 25-mL measuring flask and volume was completed to the mark with methanolic $\mathrm{HCl}$. The values of $\mathrm{DD}^{1}$ of $\mathrm{CHP} / \mathrm{MP}$ and DX/MP (standard divisor was $12 \mu \mathrm{g} \mathrm{mL}^{-1}$ MP) with variable concentrations of standard solutions of CHP (10-30 $\left.\mu \mathrm{g} \mathrm{mL}^{-1}\right)$ and DX (5 $14 \mu \mathrm{g} \mathrm{m}^{-1}$ ) at the above selected zero-crossing wavelengths were recorded. The calibration graph for each drug was constructed by plotting 
these values against the corresponding concentrations. The regression equations were computed for CHP and DX.

\section{Discrete wavelet transform-PLS method (DWT-PLS)}

\section{Construction of a training set}

A training set composed of 17 mixtures was prepared by diluting different volumes of each of CHP, DX, MP and PP working solutions into a series of 25-mL measuring flasks, each flask was spiked with $250 \mu \mathrm{g}$ of CHP and $125 \mu \mathrm{g}$ of DX, in addition to mixture no. 18 that contains spiked concentrations of CHP and DX, $10 \mu \mathrm{g} \mathrm{mL}^{-1}$ of MP and $2 \mu \mathrm{g} \mathrm{mL} \mathrm{m}^{-1}$ of $\mathrm{PP}$, all flasks were diluted to volume with methanolic $\mathrm{HCl}$. The absorption spectra of all 18 mixtures were recorded between 200-300 nm. Reject the regions from $200-215$ $\mathrm{nm}$ and above $290 \mathrm{~nm}$. Mean centering of the data was performed. The data points of the spectra were collected at every $1 \mathrm{~nm}$.

\section{Assay of laboratory-prepared mixtures}

Different synthetic mixtures containing various concentrations of CHP, DX, MP and PP were prepared by transferring accurate volumes of the four components and diluted to the volume with methanolic $\mathrm{HCl}$. These synthetic mixtures were used to check the performance of the developed models.

\section{Application to a pharmaceutical preparation (phenadone syrup)}

Five $\mathrm{mL}$ of phenadone syrup equivalent to $2 \mathrm{mg}$ of CHP, $0.5 \mathrm{mg}$ of DX, $5 \mathrm{mg}$ of MP and $1 \mathrm{mg}$ of $\mathrm{PP}$ was diluted to $100 \mathrm{~mL}$ with methanolic $\mathrm{HCl}$, further dilution was made by taking $5 \mathrm{~mL}$ of the above solution in 25-mL measuring flask, $250 \mu \mathrm{g}$ of CHP and $125 \mu \mathrm{g}$ of DX were spiked and volume was completed by methanolic $\mathrm{HCl}$. The general calibration was followed and the concentration of CHP and DX was calculated.

\section{RESULTS}

CHP is co formulated with DX in phenadone syrup and MP and PP are present as preservatives. Figure 1 shows the chemical structure of CHP and DX. The severe overlap between the absorption spectra of CHP, DX, MP and PP is anticipated in Figure 2.

\section{DD ${ }^{1}$ spectrophotometric method}

The ratio-spectrum is obtained by dividing the absorption spectrum of the mixture by standard spectrum of one of the components followed by calculation of the first derivative of the ratiospectrum and $D^{1}$ values of other components were measured at suitably selected zerocrossing points. The concentrations are then determined from their respective calibration curves. Figure 3 shows the first derivatives of ratio-spectra of the standard solutions CHP/MP and DX/MP using $12 \mu \mathrm{g} \mathrm{mL}^{-1}$ of MP as a divisor. The arrows indicate the zero-crossing wavelengths selected for determination of $\mathrm{CHP}$ and DX. The calibration graphs for each drug were achieved by plotting the values of the first derivative of the ratio-spectra at the selected wavelengths against the corresponding variable concentrations of CHP and DX.

For determination of $\mathrm{CHP}$ and $\mathrm{DX}$ in laboratory prepared mixtures, fixed amount of both drugs should be added to each experiment to increase their absorbance to the linear limit then subtract these concentrations before calculating the claimed concentrations of the two drugs. Replicate determination of six synthetic quaternary mixtures of CHP, DX, MP and PP were performed to test specificity of the method. The results for DX determination were not satisfactory as seen in Table 1. For CHP, The results were satisfactory as anticipated in Table 1. Assay validation sheet of the proposed DD1 zero-crossing method for CHP determination was presented in Table 2.<smiles>CN(C)CCC(c1ccc(Cl)cc1)c1ccccn1</smiles>

Chlorpheniramine maleate (CHP)

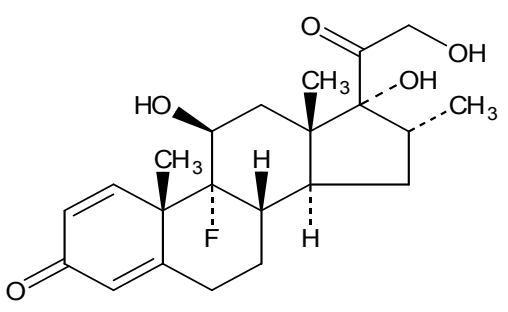

Dexamethasone (DX)

Figure 1: Chemical structures of Chlorpheniramine maleate and Dexamethasone 


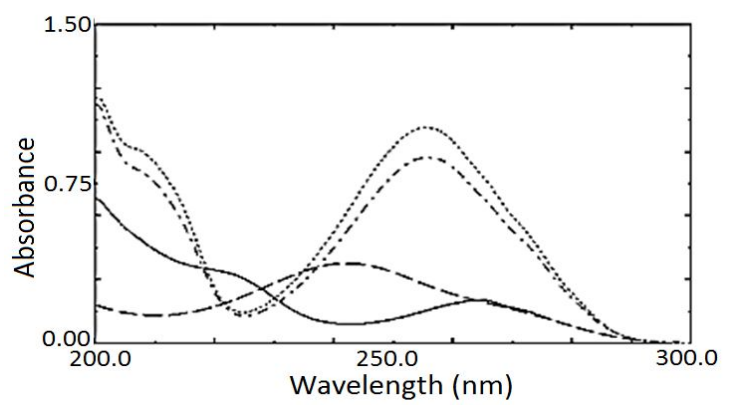

Figure 2: Absorption spectra for CHP (- - ), DX (--$-), \operatorname{MP}(\ldots \ldots)$ and PP (. . . ) each $10 \mu \mathrm{g} \mathrm{mL}-{ }^{1}$

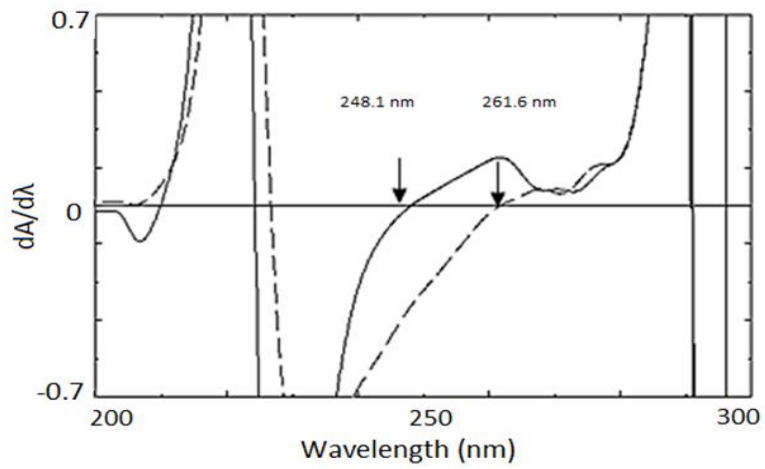

Figure 3: First derivative of the ratio spectra of $\mathrm{CHP}$ ( - ) and DX (-----) each $14 \mu \mathrm{gL}^{-1}$ using MP (12 $\mu \mathrm{g}$ $\mathrm{mL}^{-1}$ ) as a divisor

Table 1: Determination of CHP and DX in laboratory prepared mixtures by the proposed $D D^{1}$ method

\begin{tabular}{lcccccc}
\hline $\begin{array}{l}\text { Mix. } \\
\text { no. }\end{array}$ & \multicolumn{3}{c}{$\begin{array}{c}\text { Mix. composition } \\
\left(\boldsymbol{\mu g} \mathbf{~ m L}^{-1}\right)\end{array}$} \\
\hline & CHP & DX & MP & PP & CHP & DX \\
1 & 14 & 6 & 10 & 2 & 101.13 & 89.34 \\
2 & 22 & 10 & 6 & 1.2 & 99.71 & 95.35 \\
3 & 22 & 6 & 2 & 0.4 & 100.25 & 91.86 \\
4 & 14 & 14 & 4 & 0.8 & 100.85 & 99.29 \\
5 & 30 & 8 & 10 & 2 & 99.05 & 92.77 \\
6 & 18 & 14 & 6 & 1.2 & 100.49 & 99.32 \\
\hline $\begin{array}{l}\text { Mean } \\
\text { R.S.D. * \% }\end{array}$ & & & & 100.25 & 94.66 \\
& & & & & 0.764 & 4.083 \\
\hline
\end{tabular}

\section{DWT-PLS method}

After DWT, the signal will be described by the wavelet transform coefficients so it is an important step to suppress the small coefficients by thresholding. Figure 4 shows the absolute values of wavelet coefficient vector sorted by magnitude. It is clear that small number of the coefficients (25 coefficients) whose absolute value is greater than 0.045 ; most of them are small enough to be suppressed. Thus by removing these coefficients, signal denoising and compression can be done in the wavelet domain.

Table 2: Assay parameters and method validation obtained by applying the proposed $D D^{1}$ method for CHP determination

\begin{tabular}{ll}
\hline Parameter & DD ${ }^{1}$ method \\
\cline { 2 - 2 } & CHP \\
\hline Range $\left(\mu \mathrm{g} \mathrm{m}^{-1}\right)$ & $10-30$ \\
Slope & 0.0126 \\
Intercept & 0.0026 \\
Mean & 100.33 \\
S.D. & 0.709 \\
Variance & 0.503 \\
Coff. of variation & 0.007 \\
Correl. Coef. $(\mathrm{r})$ & 0.9999 \\
LOD ${ }^{*}\left(\mu \mathrm{gL} \mathrm{mL}^{-1}\right)$ & 1.458 \\
LOQ $\left.{ }^{-1} \mu \mathrm{gL}^{-1}\right)$ & 4.419 \\
R.S.D. $\% * * \mathrm{a}$ & $100.33 \pm 0.709$ \\
R.S.D. \%**b & $100.45 \pm 1.735$ \\
\hline
\end{tabular}

*Limit of detection (LOD) and limit of quantification (LOQ) were determined by calculation

${ }^{* *} R S D \%{ }^{a}, R S D \%{ }^{b}$ the intra-day, inter-day respectively $(n=4)$ relative standard deviation

The denoising and compression effectiveness mainly depends on the wavelet filter and resolution level. In this work root mean square error (RMSE) method was used as the criterion for simultaneous denoising and compression. The optimal filter is defined as that for which the RMSE is a minimum. The RMSE method is applied to a single spectrum so the mean spectrum of the calibration set was used for this purpose. Table 3 shows the composition of the training set.

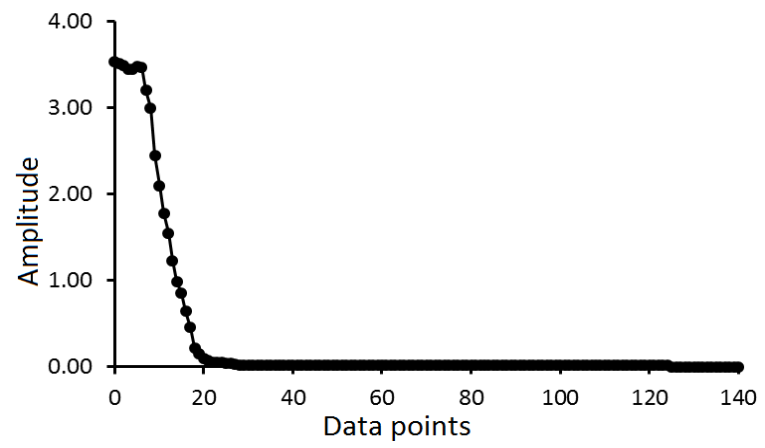

Figure 4: Plot of the absolute values of coefficient vector sorted by magnitude obtained by applying DWT to the simulated signal.

Different wavelet bases at different resolution level were tested on the mean spectrum like Daubechies wavelet family, Symlmet family and Coiflet family at different levels (Tables 4 and 5) using compression ratio 5 (i.e. using $20 \%$ of the total coefficients). It can be seen that RMSE 
Table 3: Determination of CHP and DX in calibration set by the proposed DWT-PLS method

\begin{tabular}{|c|c|c|c|c|c|c|}
\hline \multirow{2}{*}{ Mix. no. } & \multicolumn{4}{|c|}{$\begin{array}{l}\text { Mix. composition } \\
\left(\mu \mathrm{g} \mathrm{mL}^{-1}\right)\end{array}$} & \multicolumn{2}{|c|}{$\begin{array}{c}\text { Recovery \% } \\
\text { DWT-PLS method }\end{array}$} \\
\hline & CHP & DX & MP & PP & CHP & DX \\
\hline 1 & 22 & 6 & 2 & 0.4 & 99.2 & 99.74 \\
\hline 2 & 14 & 14 & 4 & 0.8 & 101.22 & 100.28 \\
\hline 3 & 30 & 8 & 10 & 2 & 99.09 & 102.89 \\
\hline 4 & 18 & 14 & 6 & 1.2 & 99.12 & 100.40 \\
\hline 5 & 30 & 10 & 2 & 0.4 & 101.12 & 99.52 \\
\hline 6 & 22 & 8 & 2 & 0.4 & 101.35 & 101.12 \\
\hline 7 & 18 & 8 & 8 & 1.6 & 101.14 & 100.35 \\
\hline 8 & 18 & 12 & 10 & 2 & 101.96 & 100.04 \\
\hline 9 & 26 & 14 & 8 & 1.6 & 99.75 & 100.17 \\
\hline 10 & 30 & 12 & 6 & 1.2 & 101.56 & 99.55 \\
\hline 11 & 26 & 10 & 10 & 2 & 98.24 & 99.46 \\
\hline 12 & 22 & 14 & 10 & 2 & 101.19 & 99.26 \\
\hline 13 & 30 & 14 & 2 & 0.4 & 99.76 & 100.23 \\
\hline 14 & 30 & 6 & 8 & 1.6 & 99.85 & 97.39 \\
\hline 15 & 14 & 12 & 2 & 0.4 & 98.09 & 99.53 \\
\hline 16 & 26 & 6 & 6 & 1.2 & 99.84 & 100.36 \\
\hline 17 & 14 & 10 & 8 & 1.6 & 101.78 & 99.62 \\
\hline 18 & 10 & 5 & 10 & 2 & 99.97 & 99.98 \\
\hline Mean & & & & & 100.24 & 99.99 \\
\hline R.S.D. * & & & & & 1.207 & 1.080 \\
\hline
\end{tabular}

${ }^{*}$ Relative standard deviation

Table 4: Root mean square error (RMSE) between experimental UV spectrum of 4 components of phenadone syrup and reconstructed signal by DWT with different filters and resolution level $\mathrm{J}=4(\mathrm{CR}=5)$

\begin{tabular}{clllll}
\hline Filter & RMSE & Filter & RMSE & Filter & RMSE \\
\hline Daub2 & 0.0186 & Sym2 & 0.0186 & Coif1 & 0.0202 \\
Daub4 & 0.0146 & Sym4 & 0.0233 & Coif2 & 0.0191 \\
Daub6 & 0.0186 & Sym6 & 0.0239 & Coif3 & 0.0270 \\
Daub8 & 0.0203 & Sym8 & 0.0236 & Coif4 & 0.0244 \\
Daub10 & 0.0315 & Sym10 & 0.0239 & Coif5 & 0.0361 \\
Daub12 & 0.0396 & Sym12 & 0.0317 & & \\
Daub14 & 0.0661 & Sym14 & 0.0270 & & \\
\hline
\end{tabular}

Table 5: Root mean square error (RMSE) between experimental UV spectrum of 4 components of Phenadone syrup and reconstructed signal by WT with wavelet filter Daubechies4 and different resolution levels $(\mathrm{CR}=5)$

\begin{tabular}{cc}
\hline Resolution level $(\mathbf{J})$ & RMSE \\
\hline 2 & 0.0121 \\
3 & 0.0075 \\
4 & 0.0146 \\
5 & 0.0107 \\
6 & 0.0186 \\
\hline
\end{tabular}

reaches minimum when resolution level is 3 using db4 as wavelet basis. The DWT was then applied to the training and validation set and the coefficients determined by RMSE method were kept for PLS-1 calibration for each component separately. The concentrations of CHP and DX, in their quaternary mixtures with the parabens, were calculated with three latent variables chosen by Haaland's and Thomas method [16]. Actual concentration and recoveries of $\mathrm{CHP}$ and
DX in training set and validation set are listed in Tables 3 and 6 respectively.

The validation of the developed WT_PLS model was assessed using several diagnostic tools (Table 7). These tools were grouped into two categories: model diagnostic tools that are used to determine the quality of the model, and sample diagnostic tools which are used to study the relationship between the samples and to identify unusual samples. The predicted concentrations of the validation samples were plotted against the true concentration values. This was used to determine whether the model accounted for the concentration variation in the validation set. All plots had a slope of nearly one and an intercept close to zero (Table 7). Root mean square error of prediction (RMSEP) was another diagnostic tool for examining the errors in the predicted concentrations, it indicates both the precision and accuracy [17]. The results in 
Table 6: Determination of CHP and DX in validation set by the proposed DWT-PLS method

\begin{tabular}{lcccccc}
\hline Mix. no. & \multicolumn{3}{c}{ Mix. Composition $\left(\boldsymbol{\mu g} \mathbf{~ m L}^{-1}\right)$} & \multicolumn{2}{c}{ Recovery \% } & DWT-PLS \\
\cline { 2 - 7 } 1 & $\mathbf{C H P}$ & $\mathbf{D X}$ & $\mathbf{M P}$ & $\mathbf{P P}$ & $\mathbf{C H P}$ & $\mathbf{D X}$ \\
\cline { 2 - 7 } 2 & 14 & 8 & 6 & 1.2 & 99.54 & 99.49 \\
3 & 22 & 12 & 8 & 1.6 & 101.80 & 99.98 \\
4 & 26 & 12 & 4 & 0.8 & 99.09 & 101.62 \\
5 & 26 & 8 & 2 & 0.4 & 99.88 & 98.04 \\
6 & 18 & 6 & 4 & 0.8 & 98.55 & 100.86 \\
7 & 18 & 10 & 2 & 0.2 & 99.32 & 99.56 \\
8 & 14 & 6 & 10 & 2 & 99.72 & 99.36 \\
Mean & 22 & 10 & 6 & 1.2 & 99.99 & 100.75 \\
R.S.D. * \% & & & & & 99.74 & 99.96 \\
\hline
\end{tabular}

${ }^{*}$ Relative standard deviation

Table 7: Summary of results obtained by applying the diagnostic tools for model validation of the DWT-PLS method

\begin{tabular}{lcc}
\hline \multirow{2}{*}{ Validation parameter } & \multicolumn{2}{c}{ DWT-PLS } \\
\cline { 2 - 3 } & CHP & DX \\
\hline a) Predicted vs. known concentration plot & \\
1- Slope & 1.0036 & 1.0191 \\
2- Intercept & 0.1163 & 0.1673 \\
3- Correlation & 0.9991 & 0.9993 \\
coefficient & & \\
\hline b) Residual vs. actual & 0.396 & 0.1944 \\
$\begin{array}{l}\text { concentration plot }( \pm \\
\text { error in prediction) }\end{array}$ & & \\
\hline c) RMSEP * & 0.1790 & 0.1420 \\
\hline
\end{tabular}

${ }^{*}$ Root mean square error of prediction

Table 7 indicate the high predictive abilities of the suggested model.

The results obtained for the analysis of the analytes in the pure powdered from by the suggested methods were statistically compared with those obtained by applying one of reported method [11] (HPLC analysis using C18 column and $0.005 \mathrm{M}$ heptane sulphonic acid sodium salt in bi-distilled water: acetonitrile $(70: 30 \mathrm{v} / \mathrm{v}), \mathrm{pH}$ 5). The results obtained were compared for the mean and the standard deviation using the t-test and F-test respectively. There were no significant differences between the results as shown in Table 8. In addition, the results found were in good agreement with the data indicated in the formulations given by the manufacturer.

One-way ANOVA was applied for the purpose of comparison of developed methods. Table 9 shows that there was no significant difference between them for the determination of $\mathrm{CHP}$ in presence of DX, MP and PP.

\section{Application to pharmaceutical preparation}

The proposed methods were successfully applied for the determination of CHP in Phenadone syrup in presence of parabens while DX was determined only by DWT-PLS method. The results are shown in Table 10. Each value indicated is the mean of 4 determination of the same commercial batch. The validity of the proposed methods was further assessed by applying the standard addition technique. Results obtained are shown in Table 10.

Table 8: Statistical comparison for the results obtained by the proposed methods and reported HPLC method [11] for the analysis of CHP and DX in pure powder form

\begin{tabular}{lccccc}
\hline \multirow{2}{*}{ Item } & $\begin{array}{c}\mathbf{D D}^{1} \\
\text { method }\end{array}$ & \multicolumn{2}{c}{ DWT-PLS method } & \multicolumn{2}{c}{$\begin{array}{c}\text { Reported HPLC } \\
\text { method }\end{array}$} \\
\cline { 2 - 6 } & $\mathbf{C H P}$ & $\mathbf{C H P}$ & $\mathbf{D X}$ & $\mathbf{C H P}$ & DX \\
\hline Mean & 100.33 & 100.24 & 99.99 & 99.93 & 99.96 \\
R.S.D. & 0.909 & 1.207 & 1.080 & 1.920 & 1.746 \\
Variance & 0.826 & 1.457 & 1.166 & 3.686 & 3.049 \\
$\mathrm{~N}$ & 6 & 18 & 18 & 7 & 7 \\
F test & 4.462 & 2.530 & 2.615 & & \\
& $(4.95)$ & $(2.70)$ & $(2.70)$ & & \\
Student's & 1.164 & 0.487 & 0.052 & & \\
t test & $(2.201)$ & $(2.069)$ & $(2.069)$ & & \\
\hline
\end{tabular}

* Figures in parentheses are theoretical values for $t$ - and $F$ - at confidence level of $95 \%$ 
Table 9: One-way ANOVA testing for the different proposed methods used for the determination of $\mathrm{CHP}$

\begin{tabular}{ccccc}
\hline $\begin{array}{c}\text { Source of } \\
\text { variation }\end{array}$ & DF & $\begin{array}{c}\text { Sum of } \\
\text { squares }\end{array}$ & $\begin{array}{c}\text { Mean } \\
\text { square }\end{array}$ & F-value \\
\hline Between exp. & 1 & 0.893 & 0.893 & 1.152 \\
\hline Within exp. & 12 & 9.305 & 0.775 & \\
\hline
\end{tabular}

There was no significance difference between the methods using oneway ANOVA (F-test), where F tabulated $=4.747$ at $p<0.05$

Table 10: Applying standard addition technique for determination of CHP by the two proposed methods and DX by the DWT-PLS method in phenadone syrup (Batch No. 630351)

\begin{tabular}{|c|c|c|c|c|c|}
\hline \multirow{2}{*}{$\begin{array}{c}\text { Sample } \\
\text { No. }\end{array}$} & \multicolumn{2}{|c|}{$\begin{array}{c}\text { Authentic } \\
\text { added } \\
\mu \mathrm{g} \mathrm{mL}^{-1}\end{array}$} & \multirow{2}{*}{$\begin{array}{c}\text { DD }{ }^{1} \text { method } \\
\begin{array}{c}\text { Recovery \% of } \\
\text { CHP }\end{array}\end{array}$} & \multicolumn{2}{|c|}{ DWT-PLS method } \\
\hline & CHP & DX & & $\begin{array}{c}\text { Recovery \% of } \\
\text { CHP }\end{array}$ & $\begin{array}{c}\text { Recovery \% } \\
\text { of DX }\end{array}$ \\
\hline 1 & 2 & 1 & 99.40 & 98.50 & 99.30 \\
\hline 2 & 4 & 2 & 99.08 & 100.15 & 98.85 \\
\hline 3 & 6 & 3 & 99.53 & 101.55 & 102.07 \\
\hline \multicolumn{3}{|c|}{ Mean \pm R.S.D. } & $99.34 \pm 0.237$ & $100.07 \pm 1.527$ & $100.07 \pm 1.742$ \\
\hline \multicolumn{3}{|c|}{$\begin{array}{c}\text { Found of CHP and DX } \\
\text { in phenadone syrup* }(\% \\
\pm \text { R.S.D.) }\end{array}$} & $100.33 \pm 2.497$ & $100.37 \pm 0.696$ & $101.15 \pm 1.309$ \\
\hline
\end{tabular}

\section{DISCUSSION}

In this work, quantitation of CHP and DX in this quaternary mixture was tried using first derivative of the ratio spectra $\left(\mathrm{DD}^{1}\right)$ and the smart DWTPLS method. Derivative spectrophotometry has received increasing attention over the last few decades with regard to the assay of the drugs in dosage forms and biological fluids as a result of the development of microcomputer technology which allows the rapid generation of the derivative spectra and its application for the simultaneous determination of mixtures with closely overlapping absorption spectra $[16,18,19]$.

In 1990, Salinas et al [18] developed a spectrophotometric method based on the use of the first derivative of the ratio spectra for resolving binary mixture. The method was then extended by Berzas et al [20] to resolving ternary mixture with overlapped spectra. The ratiospectra zero-crossing first derivative spectra method is based on the simultaneous use of the first derivative of the ratio-spectra mixtures, followed by measurements at the zero-crossing wavelengths of first derivative of the ratio-spectra of single components. As accurate choice of the standard divisors and working wavelengths are of paramount importance $[16,18]$, in this method various divisor concentrations were tested and the zero-crossing wavelengths were determined. For all subsequent measurements standard spectrum of $12 \mu \mathrm{g} \mathrm{mL}^{-1}$ of MP was chosen as a divisor to determine CHP and DX. This divisor represents the best compromise in terms of sensitivity, signal to noise ratio and reproducibility.

The influence of the wavelength interval $(\Delta \lambda)$ for obtaining the first derivative was tested and a wavelength interval of $4 \mathrm{~nm}$ was suitable $(\Delta \lambda=4$ $\mathrm{nm}$ ). A linear correlation was obtained between $D D^{1}$ values at selected wavelengths and the corresponding concentration in the range of $10-$ $30 \mu \mathrm{gL}^{-1}$ for CHP and $5-14 \mu \mathrm{g} \mathrm{m}^{-1}$ for DX. The regression equations were computed and found as follows:

$\mathrm{DD}^{1}{ }_{261.6}(\mathrm{CHP})=0.0126 \mathrm{C}_{1}+00.0026 ; \mathrm{r}=$ 0.9999

$\mathrm{DD}^{1}{ }_{248.1}(\mathrm{DX})=0.0263 \mathrm{C}_{2}+0.0014 ; r=0.9998$

where: $C_{1}$ is CHP concentrations, $C_{2}$ is $D X$ concentrations, r: correlation coefficient.

On application of the $D D^{1}$ method for determination of $\mathrm{DX}$ in different laboratory 
prepared mixtures, the percentages recovery were not accurate. This may be due to that, the selected wavelength for DX determination (248.1) lay on the slope of DX band which subject the subsequent analysis of $D X$ to error. This error is indicated by the higher value of R.S.D. (> $4 \%$ ) and deviation of the mean R \% from $100 \%$ value as seen in Table 1. Different divisors were tried but no maxima appeared for DX in the mixture.

Wavelet transform (WT) is similar to the Short time Fourier transform (STFT) in that both techniques analyze an input signal in blocks by translation (movement) of a basis function. This basis function in FT is sine wave and it is called wavelet in WT.

There are two approaches for WT, discrete wavelet transform (DWT) and continuous wavelet transform (CWT). DWT is easier to implement than continuous wavelet transform (CWT). The CWT is computed at every possible scale while in DWT, the scale is chosen based on powers of two so called dyadic scales. An efficient way to implement DWT is the Mallat algorithm [21]. In DWT, the original signal is converted to wavelet coefficients. Many of the wavelet coefficients are very small in amplitude ('detailed coefficients') and can be removed without major loss in the information content of the signal.

There are many methods to determine the threshold value below which the wavelet coefficients can be removed safely [21]. The threshold defined by RMSE of the reconstructed signal is the most commonly used method because it is a measure of the quality of compression. In order to obtain optimal filter and resolution level $\mathrm{j}$ for the spectrum, the RMSE between the original measured spectrum and reconstructed signal by different wavelet filters and different resolution level j were investigated. Once the optimal filter and resolution level were selected, all individual spectra were transformed using this filter. Thereafter, the optimal number of the wavelet coefficients was used to construct $X_{w}$ matrix, which contains the important information. $X_{w}$ was used for calibration in wavelet domain i.e. no reconstruction of the signal was done. The index of the retained coefficients is kept for use with future samples.

\section{CONCLUSION}

This findings show the superiority of DWT-PLS over $D^{1}$ method in solving this complex mixture (particularly in estimation of DX concentration). DWT-PLS method is considered powerful alternatives for traditional derivative ratio spectrophotometry. The applied method combines rapidness and simplicity advantages of traditional spectrometric methods together with other important analytical merits, such as sensitivity and specificity. The developed method can be applied to the routine quality control analysis of $\mathrm{CHP}$ and $\mathrm{DX}$ in their combined oral liquid dosage form without prior separation or interference from impurities/excipients.

\section{ACKNOWLEDGEMENT}

The authors would like to extend their sincere appreciation to the Deanship of Scientific Research at King Saud University for its funding of this research through the Research Group Project no. RGP-VPP-322.

\section{REFERENCES}

1. Alsberg BK, Woodward $A M$, Kell DB. An introduction to wavelet transforms for chemometricians: A timefrequency approach. Chemometrics and Intelligent Laboratory Systems 1997; 37(2): 215-239.

2. Cocchi M, Hidalgo-Hidalgo-de-Cisneros J, NaranjoRodrıguez I, Palacios-Santander J, Seeber R, Ulrici A. Multicomponent analysis of electrochemical signals in the wavelet domain. Talanta 2003; 59(4): 735-749.

3. Lu X, Liu H, Kang J, Cheng J. Wavelet frequency spectrum and its application in analyzing an oscillating chemical system. Analytica chimica acta 2003; 484(2): 201-210.

4. Kramer R. Chemometric techniques for quantitative analysis: Marcel Dekker Incorporation; 1998.

5. Leung AK-m, Chau F-t, Gao J-b. A review on applications of wavelet transform techniques in chemical analysis: 1989-1997. Chemometrics and Intelligent Laboratory Systems 1998; 43(1): 165-184.

6. Zhang Y, Mo J, Xie T, Cai P, Zou X. Spline wavelet selfconvolution in processing overlapped peaks in capillary electrophoresis. Analyst 2000; 125(7): 13031305.

7. Depczynski $U$, Jetter $K$, Molt $K$, Niemöller $A$. The fast wavelet transform on compact intervals as a tool in chemometrics: II. Boundary effects, denoising and compression. Chemometrics and Intelligent Laboratory Systems 1999; 49(2): 151-161.

8. Esteban-Díez I, González-Sáiz J, Gómez-Cámara D, Millan CP. Multivariate calibration of near infrared spectra by orthogonal WAVElet correction using a genetic algorithm. Analytica Chimica Acta 2006; 555(1): 84-95

9. Santos RNFd, Galvão RKH, Araujo MCU, Silva ECd. Improvement of prediction ability of PLS models employing the wavelet packet transform: $A$ case study concerning FT-IR determination of gasoline parameters. Talanta 2007; 71(3): 1136-1143.

Trop J Pharm Res, May 2015; 14(5): 866 
10. Budavari S, O'Neal M, Smith A, Heckelman P, Kinneary $J$. The Merck Index. An Encyclopedia of Chemicals, Drugs, and Biologicals. 12th edn. Whitehouse Station, NJ: Merck \& Co. Inc; 1996.

11. Moyano MA, Rosasco MA, Pizzorno MT, Segall Al. Simultaneous determination of chlorpheniramine maleate and dexamethasone in a tablet dosage form by liquid chromatography. Journal of AOAC International 2005; 88(6): 1677-1683.

12. Hattori $T$, Washio $Y$, Kamiya $N$, Itoh $Y$, Inoue M. High performance liquid chromatographic analysis of drugs. I. Simultaneous determination of dexamethasone and chlorpheniramine maleate in ointment (author's transl)]. Yakugaku zasshi: Journal of the Pharmaceutical Society of Japan 1979; 99(5): 537-539.

13. El-Yazbi FA, Hammud HH, Assi SA. New spectrofluorometric application for the determination of ternary mixtures of drugs. Analytica chimica acta 2006; 580(1): 39-46.

14. Goicoechea HC, Collado MS, Satuf ML, Olivieri AC. Complementary use of partial least-squares and artificial neural networks for the non-linear spectrophotometric analysis of pharmaceutical samples. Analytical and bioanalytical chemistry 2002; 374(3): 460-465

15. El-Yazbi F, Korany M, Abdel-Razak O, Elsayed M. Derivative spectrophotometric determination of some corticosteroids in combinations with other drugs.
Journal-Association of Official Analytical Chemists 1986; 69(4): 614-618.

16. Haaland DM, Thomas EV. Partial least-squares methods for spectral analyses. 1. Relation to other quantitative calibration methods and the extraction of qualitative information. Analytical Chemistry 1988; 60(11): 11931202.

17. Beebe K, Pell R, Seasholtz M. Chemometrics, A Practical Guide. New York: John Wiley \& Sons, inc; 1998.

18. Espinosa-Mansilla A, Salinas $F$, De Orbe Paya $I$. Simultaneous determination of sulfadiazine, doxycycline, furaltadone and trimethoprim by partial least squares multivariate calibration. Analytica chimica acta 1995; 313(1): 103-112.

19. Leardi R, Seasholtz MB, Pell RJ. Variable selection for multivariate calibration using a genetic algorithm: prediction of additive concentrations in polymer films from Fourier transform-infrared spectral data. Analytica Chimica Acta 2002; 461(2): 189-200.

20. Berzas Nevado J, Rodriguez Flores J, Guiberteau Cabanillas C, Villasenor Llerena $M$, Contento Salcedo A. Resolution of ternary mixtures of Tartrazine, Sunset yellow and Ponceau $4 R$ by derivative spectrophotometric ratio spectrum-zero crossing method in commercial foods. Talanta 1998; 46(5): 933-942.

21. Chau FT, Liang YZ, Gao J, Shao XG. Chemometrics: from basics to wavelet transform. Weinheim, Germany: Wiley-VCH Verlag GmbH; 2004. 